\title{
Wykorzystanie rentgenowskiej mikrotomografii komputerowej i cyfrowej analizy obrazu do petrologicznej charakterystyki skał węglanowych
}

\author{
Piotr Jan Strzelecki ${ }^{1}$, Adam Fheed ${ }^{1}$, Natalia Radzik ${ }^{1}$, Anna Świerczewska ${ }^{1}$
}

\begin{abstract}
X-ray microtomography and digital image analysis application to a petrological characterization of carbonates. Prz. Geol., 67: 195-197; doi: 10.7306/2019.19

A b s tr a c t. The paper briefly describes a possible application of X-ray computed microtomography studies followed by digital image analysis, enabling petrological assessment of carbonate rocks. The contribution presents an example of a complex, qualitative and quantitative approach aiming at deriving shape, geometry and spatial orientation of rock components as applied for a carbonate reservoir rock sample from the Zechstein Limestone (Ca1) strata. Apart from the basic properties of the analyzed objects, such as volume, surface area and number, detailed shape descriptors were obtained (compactness, sphericity, elongation, flatness, spareness). The presented approach allows for obtaining detailed $3 D$ results at the microscopic scale, enabling extensive characterization of the studied material geometry. The methods proposed could be applied for other rock types as well.
\end{abstract}

Keywords: X-ray microcomputed tomography, digital image analysis, porosity geometry, carbonates

Mikrotomografia komputerowa $(\mu \mathrm{CT})$ jest nieniszczącą metodą badawczą, umożliwiająca trójwymiarową wizualizację badanego obiektu. Od lat 90. XX w. obserwuje się ciągły wzrost zainteresowania tą techniką w naukach geologicznych (Harmon i in., 2006; Cnudde, Boone, 2013). Mikrotomografia komputerowa wykorzystuje zjawisko absorbcji promieniowania rentgenowskiego (por. Landis, Keane, 2010). Wynikiem skanowania $\mu \mathrm{CT}$ jest trójwymiarowy obraz badanego obiektu. Odmienne współczynniki absorpcji poszczególnych faz umożliwiają ich rozróżnie- nie. Najlepiej widoczne są więc składniki o różnej gęstości: np. przestrzeń porowa, matryca skalna czy minerały rudne. Dokładność obrazowania jest uzależniona od rozdzielczości, czyli długości boku pojedynczego woksela (trójwymiarowy piksel) i wynosi ona zazwyczaj kilka-kilkadziesiąt $\mu \mathrm{m}$. Cyfrowa analiza obrazu jest metodą powszechnie stosowaną do przetwarzania oraz analizy zdjęć. Jej niewątpliwą zaletą jest możliwość wykonania dużej liczby analiz w stosunkowo krótkim czasie. Analiza obrazu często jest traktowana jako integralny element bada-

\footnotetext{
${ }^{1}$ AGH Akademia Górniczo-Hutnicza im. Stanisława Staszica w Krakowie, Wydział Geologii, Geofizyki i Ochrony Środowiska, al. Mickiewicza 30,30-059 Kraków; piotrjanstrzelecki@gmail.com
} 
Tab. 1. Geometria i kształt wybranych porów izolowanych

Tab. 1. Geometry and shape of selected isolated porous space

\begin{tabular}{|l|c|c|c|c|c|}
\hline \multicolumn{1}{|c|}{$\begin{array}{c}\text { Parametr } \\
\text { Parameter }\end{array}$} & $\begin{array}{c}\text { Kompaktowość } \\
\text { Compactness }\end{array}$ & $\begin{array}{c}\text { Sferyczność } \\
\text { Sphericity }\end{array}$ & $\begin{array}{c}\text { Wydlużenie } \\
\text { Elongation }\end{array}$ & $\begin{array}{c}\text { Splaszczenie } \\
\text { Flatness }\end{array}$ & $\begin{array}{c}\text { Wypelnienie } \\
\text { Spareness }\end{array}$ \\
\hline Średnia / Mean & 0,047 & 0,347 & 2,014 & 1,923 & 0,516 \\
\hline Mediana / Median & 0,043 & 0,350 & 1,785 & 1,657 & 0,529 \\
\hline Minimum / Minimum & 0,003 & 0,147 & 1,032 & 1,029 & 0,100 \\
\hline Maksimum / Maximum & 0,139 & 0,518 & 8,631 & 7,476 & 0,881 \\
\hline Odchylenie standardowe / Standard deviation & 0,025 & 0,068 & 0,869 & 0,872 & 0,176 \\
\hline
\end{tabular}

nia tomograficznego. Jej nieodłączną częścią jest przetwarzanie zdjęć, tj. filtracja i segmentacja. Analizie mogą być poddane wybrane składniki skały. Wynikiem cyfrowej analizy obrazu jest zazwyczaj duża liczba danych numerycznych, reprezentujących poszczególne pomierzone parametry analizowanych obiektów. Do podstawowych parametrów i właściwości tych obiektów należą ich ilość, wielkość, objętość lub powierzchnia właściwa. Możliwy jest także bardzo szczegółowy opis geometrii, kształtu oraz rozmieszczenia poszczególnych składników skały. Ze względu na skomplikowaną więźbę skał węglanowych, w tym ich systemu porowego, możliwość obrazowania wnętrza skały, obejmująca klasyfikację oraz kwantyfikację wybranych jej cech, pozwala na dokładną charakterystykę petrologiczną tego rodzaju skał.

Celem niniejszej pracy jest kompleksowa, jakościowo-ilościowa charakterystyka petrologiczna skały węglanowej, wykonana na podstawie analizy obrazu otrzymanego metodą $\mu \mathrm{CT}$. Taka analiza umożliwia przestrzenne określenie zmienności właściwości zbiornikowych, co ma zaś istotne znaczenie w aspekcie poszukiwań węglowodorów.

\section{MATERIAL I METODY}

Analizie poddano otrzymany metodą $\mu \mathrm{CT}$ obraz próbki utworów wapienia cechsztyńskiego (Ca1) z wału wolsztyńskiego. Próbka ta została pobrana ze strefy spagowej rafy Brońska, w całości przewierconej otworem Reńsko-1. Wymiary analizowanego obrazu wynosiły $1 \times 1,5 \mathrm{~cm}$ (średnica, wysokość) przy zastosowanej rozdzielczości obrazu $15 \mu \mathrm{m}$.

Do analizy obrazu wykorzystano program Fiji (Schindelin i in., 2012), będący oprogramowaniem typu open source. Zastosowano rozszerzenie 3D ImageJ suite (Ollion i in., 2013). Właściwości geometryczne przestrzeni porowej zostały opisane przy użyciu następujących bezwymiarowych parametrów (tab. 1):

1) Kompaktowość - stosunek objętości pomierzonego obiektu do objętości kuli o ekwiwalentnej powierzchni do mierzonego obiektu;

2) Sferyczność - stosunek powierzchni kuli o objętości ekwiwalentnej mierzonemu obiektowi do rzeczywistej powierzchni tego obiektu;

3) Wydłużenie - stosunek długości największego a) do pośredniego b) promienia elipsoidy dopasowanej do mierzonego obiektu;

4) Spłaszczenie - stosunek długości pośredniego b) do najmniejszego c) promienia dopasowanej elipsoidy mierzonego obiektu;

5) Wypełnienie - stosunek objętości mierzonego obiektu do objętości dopasowanej elipsoidy.
Badania dotyczące składu mineralnego i więźby uzupełniono obserwacjami makroskopowymi, mikroskopowymi oraz analizą XRD.

\section{WYNIKI BADAŃ}

Analizowana skała to wapień dolomityczny z licznymi fragmentami mszywiołów gałązkowych i inkrustujących, ramienionogów oraz małży. Jako cement występuje kalcyt, dolomit i anhydryt. Kalcytowy mikryt jest impregnowany związkami żelaza. Baryt został stwierdzony jedynie metodą XRD. W analizie obrazu wszystkie wyszczególnione składniki zostały określone wspólnym terminem matryca skalna. Na obrazie $\mu \mathrm{CT}$ wyróżniono kilka faz różniących się gęstością, reprezentujących matrycę skalną oraz porowatość (ryc. 1). Matryca skalna jest zbudowana głównie z nierozróżnialnych na obrazie $\mu \mathrm{CT}$ kalcytu i dolomitu. Stanowi 76\% objętości badanej próbki. Pozostałe tło skalne stanowią cementy: anhydryt $(2,5 \%)$ oraz fazy mineralne o dużej gęstości, najprawdopodobniej tlenki lub też wodorotlenki żelaza $\mathrm{z}$ domieszką barytu (1,5\%). Anhydryt tworzy duże kryształy o długości do kilku mm i występuje nieregularnie w obrębie próbki, wypełniając niektóre większe pory. Pozostałe fazy mineralne tworzą mniejsze i bardziej rozproszone skupienia, pokrywające ściany porów. Porowatość całkowita wynosi $20 \%$.

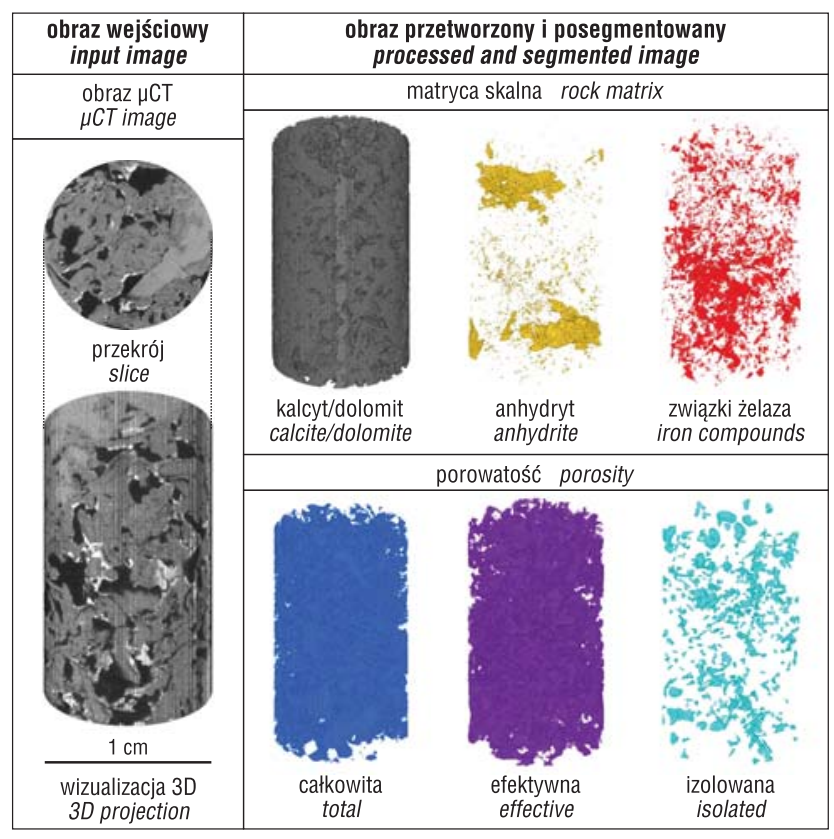

Ryc. 1. Trójwymiarowa wizualizacja skały: oryginalny plik oraz wydzielone fazy

Fig. 1. 3D projection of the rock: original image and segmented phases 
Szczegółowej analizie poddano obraz przestrzeni porowej. Wykryto 23 tys. porów, o całkowitej objętości $236 \mathrm{~mm}^{3}$ oraz łącznej powierzchni $5600 \mathrm{~mm}^{2}$. Analizując połączenia pomiędzy porami stwierdzono występowanie jednego spójnego systemu porów, zajmującego 95\% całkowitej porowatości, co stanowi 19\% objętości całej skały. System ten występuje regularnie w całej objętości próbki. Pozostałe pory nie są połączone. Na podstawie analizy $3 \mathrm{D}$ geometrii porów, zweryfikowanej obserwacjami płytek cienkich, wyróżniono porowatość typu: 1) moldycznego (po skorupach), czasem ewoluującą w większe rozmycia i kawerny; 2) międzykomponentowa, a także 3) mniejsze pustki wewnątrzkomponentowe. Te ostatnie powstały $\mathrm{w}$ zoecjach częściowo rozczłonowanych mszywiołów.

Dalszej analizie poddano obrazy izolowanych porów o objętości $>1000$ wokseli, $\left(>0,003 \mathrm{~mm}^{3}\right)$. W sumie wyodrębniono 445 porów spełniających to kryterium. Największy z nich miał objętość $0,56 \mathrm{~mm}^{3}$. Wyniki pomiarów parametrów opisujących geometrię porów zamkniętych zestawiono w tabeli 1. Zarówno kompaktowość, jak i sferyczność przyjmują kolejno bardzo niskie $(<0,1)$ oraz niskie wartości $(\sim 0,3)$. Współczynnik wypełnienia waha się od 0,1 do 0,9 . Największe izolowane pory wykazuja najlepsze dopasowanie do kształtu dyskoidalno-sferycznego (ryc. 2). Nie obserwuje się wyraźnych trendów w przestrzennym zorientowaniu poszczególnych osi elipsoid.

\section{DYSKUSJA I WNIOSKI}

Trójwymiarowe zobrazowanie przestrzeni porowej wybranej próbki skały węglanowej umożliwiło określenie genezy porowatości. Na podstawie obserwowanej geometrii porów można przypuszczać, że przestrzeń porowa powstała głównie na drodze rozpuszczania skorup ramienionogów i małży oraz zoecjów mszywiołów (por. Strzelecki, Fheed, 2018). Rozpuszczanie objęło całą próbkę, prowadząc do powstania jednego, dominującego i spójnego systemu porów, dzięki czemu przestrzeń porowa jest dobrze skomunikowana. Obliczona porowatość efektywna pozwala zaklasyfikować badaną próbkę do skał zbiornikowych wysokiej pojemności (por. Semyrka i in., 2008).

Otrzymane wyniki wskazuja, że powierzchnie izolowanych porów mają nieregularną morfologię i kształt. Świadczą o tym niewielkie wartości współczynników kompaktowości oraz sferyczności, które wraz ze wzrostem nieregularności powierzchni obiektu zbliżają się do 0 , a w przypadku idealnych sfer przyjmują wartość 1 .

Zróżnicowanie kształtu porów sugerują także wyniki otrzymane na podstawie dopasowania elipsoid, w tym długości ich osi a, b i c (ryc. 2, tab. 1). Współczynnik wypełnienia sugeruje natomiast, że elipsoidy mają raczej formę brył opisanych na obiektach, niż w nie wpisanych, co także podkreśla nieregularną geometrię tych obiektów. Brak wyraźnych trendów w przestrzennym zorientowaniu poszczególnych osi elipsoid może być wyrazem zarówno skomplikowanej geometrii porów oraz obecności kilku ich typów, jak i selektywnej cementacji oraz pierwotnego ułożenia składników skały, widocznych na obrazach 3D.

Przedstawiona charakterystyka jest przykładem wykorzystania obrazowania $\mu \mathrm{CT}$, uzupełnionego o jego cyfrowa analizę do badań petrologicznych zbiornikowej skały węglanowej. Uzyskane wyniki wskazują na duże możliwości wykorzystania obydwu metod do badania przestrzennych relacji pomiędzy poszczególnymi składnikami skały

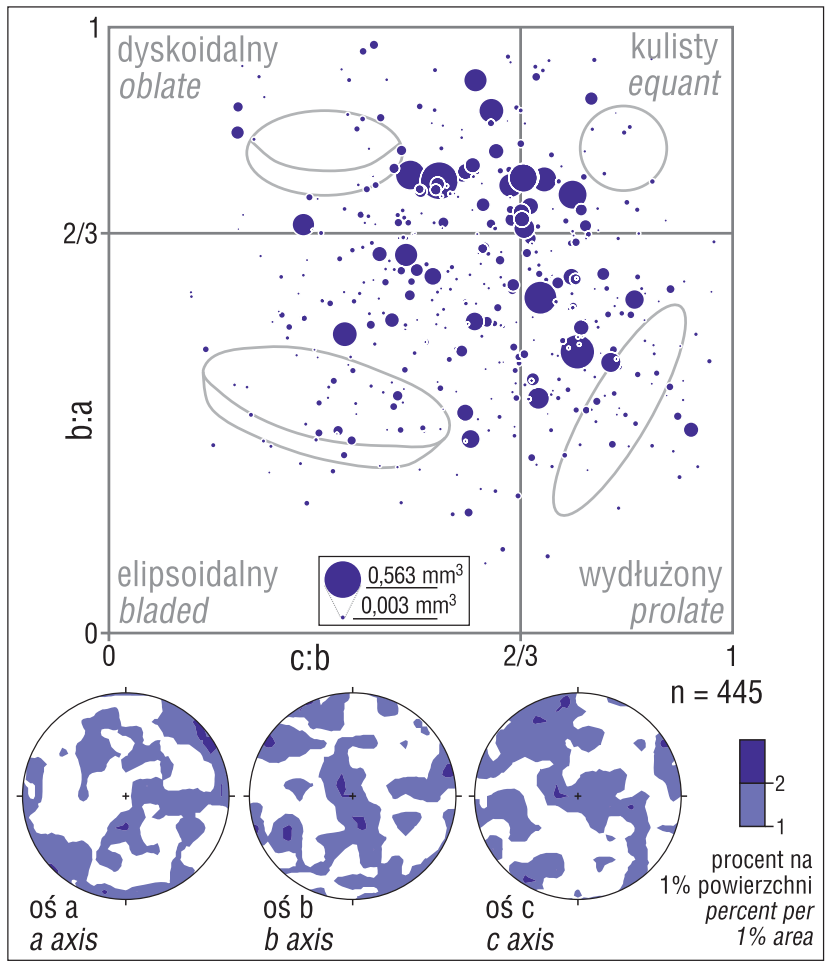

Ryc. 2. Kształt i ułożenie izolowanych porów na podstawie dopasowanej elipsoidy o osiach a, b, c; projekcja równopowierzchniowa na dolną półkulę w lokalnym układzie współrzędnych

Fig. 2. Shape and spatial orientation of isolated porosity based on ellipsoid fitting; a, b, c - ellipsoid axes; the equal-area lower hemisphere projection with a local coordinate system

oraz oceny wykształcenia przestrzeni porowej. Przedstawione podejście badawcze pozwala na kwantyfikacje geometrii przestrzeni porowej oraz składników budujących matrycę skalną i może być również stosowane do innych rodzajów skał.

Badania przeprowadzono w ramach realizacji projektu UMO-2016/23/N/ST10/00350 finansowanego przez Narodowe Centrum Nauki.

\section{LITERATURA}

CNUDDE V., BOONE M.N. 2013 - High-resolution X-ray computed tomography in geosciences: A review of the current technology and applications. Earth Sci. Rev., 123: 1-17.

HARMON R.S., VANNUCCI R., CNUDDE V., MASSCHAELE B., DIERICK M., VLASSENBROECK J., HOOREBEKE L., VAN JACOBS P. 2006 - Recent progress in X-ray CT as a geosciences tool. App. Geochem., 21: 826-832.

LANDIS E.N., KEANE D.T. 2010 - X-ray microtomography. Mat. Cha., 61: 1305-1316.

OLLION J., COCHENNEC J., LOLL F., ESCUDÉ C., BOUDIER T. 2013 - TANGO: A generic tool for high-throughput 3D image analysis for studying nuclear organization. Bioinformatics, 29: 1840-1841.

SCHINDELIN J., ARGANDA-CARRERAS I., FRISE E., KAYNIG V., LONGAIR M., PIETZSCH T., PREIBISCH S., RUEDEN C., SAALFELD S., SCHMID B., TINEVEZ J.Y., WHITE D.J., HARTENSTEIN V., ELICEIRI K., TOMANCAK P., CARDONA A. 2012 - Fiji: An open-source platform for biological-image analysis. Nat. Meth., 9: 676-682.

SEMYRKA R., SEMYRKA G., ZYCH I. 2008 - Variability of petrophysical parameters of subfacies in the Main Dolomite strata of the western Grotów Peninsula area in the light of porosimetric measurements. Geologia, 34(3): 445-468.

STRZELECKI P.J., FHEED A. 2018 - Spatial permeability estimation for carbonates - X-ray microtomography in Zechstein Limestone strata assessment. [W:] International Multidisciplinary Scientific GeoConference Surveying Geology and Mining Ecology Management, SGEM., 18 (1.4): 803-810. 